\title{
To readers
}

This is a book about varieties of the English language, both now and in the past, and about the way in which the diversity that characterises such varieties comes to be used by individuals and communities of speakers in order to achieve interpersonal, social and political goals. In other words, it is about both the linguistic form of varieties of English, and the function of those varieties in communities across the world. In order to understand why varieties of English have the form and function that they do, we will make use of general research into the relationship between language and society, a discipline known as 'sociolinguistics'. Sociolinguistics covers a wide range of intellectual inquiry, and this book will not cover all aspects of the sociolinguistic enterprise. For example, this book does not deal in any depth with the range of methodologies used to investigate sociolinguistic variation in English (see Tagliamonte 2006 for an introduction to sociolinguistic method); nor does it deal in depth with aspects of discourse structure, conversational analysis, sexism and language, and many other topics which you might expect to find in an introductory book on general sociolinguistics. What this book does is draw on selected aspects of the findings of sociolinguistic research in order to illustrate a range of interesting things about the English language.

The first part of the book is concerned primarily with the function of English in various societies (though as we will see throughout the book, it is often difficult to discuss the function of English without making some reference to aspects of linguistic form). The first chapter is concerned with English as a linguistic and as a social concept. In this chapter, we will consider what many people might consider a surprising question: is English a language? In order to answer that question, we will need to establish what is meant by both 'English' and 'language', and we will see that when we use linguistic criteria (for example, sounds, words or sentences) to try to establish what 'English' is, in order to distinguish it from other languages such as 'French', 'Navajo' or 'Scots', some very 
interesting and problematic issues arise. When we use social, cultural or geographic criteria (for example, that there is a correct variety of English, or that English can be defined by its use in specific domains, or that English is the language spoken in particular places such as England and Australia) to try to establish what 'English' is, we run into other, equally interesting, and equally problematic issues. The second chapter looks at communities and individuals who speak English. In this chapter, we look at three different things: the notion of a speech community; a global network of English speakers; and the relationship between the individual and the English language. The third chapter of this book considers English explicitly as a sociopolitical concept, where we look at the place of English in (often government-authorised) language planning, and domains of English use in multilingual communities.

The second part of the book looks more closely at formal characteristics of varieties of English. Chapter 4 begins by locating the study of social variation in English within a larger context of dialectology (the study of varieties of language, usually regional varieties). We will also consider some of the ways in which English varies depending on the social characteristics of the speaker, the social context in which the discourse takes place, and the nature of the speaker's audience. The intersection of dialectology and sociolinguistics in terms of the social dimensions of geographic space is also discussed. Chapter 5 is concerned with the relationship between social variation in present-day English and the study of ongoing change in the language. We examine some of the insights that variationist sociolinguistics has provided for the study of language change in general, and change in varieties of English in particular. In this chapter, we will also consider the important issue of language maintenance - given the power associated with Standard English, which has grown since the beginnings of the standard variety about five hundred years ago, why do non-standard, vernacular varieties of English continue to thrive? Chapter 6 continues the theme of language variation and change by looking at sociolinguistics and the history of English. In this chapter we cover topics from all periods of the history of English, from whether we can sensibly talk about social variation in the earliest recorded forms of English in the Anglo-Saxon period, through to the sociolinguistics of polite and refined English usage in the nineteenth century, and the future of English.

Chapters 7 and 8 are about contact, and the linguistic consequences of contact between speakers of different varieties. These varieties might be different languages, or they might be dialects of English - what we see is that the linguistic processes involved in both cases are very similar. Chapter 7 looks at English in contact with other languages, picking up 
some of the themes from Chapter 3, but concentrating on the formal properties of English in such contact scenarios, where language changes as a result of normal interaction between speakers, rather than authorised intervention. What linguistic properties or characteristics are found in varieties which have emerged from short-term and long-term contact between speakers of English and speakers of other languages? Chapter 8 looks at dialect contact, examining the kinds of varieties that emerge both through long-term contact at boundaries between dialect areas of English, and also as a result of mass migration to newly created communities. These communities may have been established fairly recently (as in the case of new towns in the United Kingdom) or much longer ago (as in the case of migrations to New Zealand).

The ninth chapter is concerned with the place of sociolinguistics within a larger theory of the structure of English, and of language more generally. We will consider the interplay of linguistic and social constraints on variation, and then outline some of the ways in which some theories have attempted to incorporate sociolinguistic findings into their framework for language structure, as well as considering the justification for such an incorporation. How do we bring together the important findings from quantitative sociolinguistics and the equally important findings from theoretical linguistics? This is a challenging and exciting aspect of research into why language varies in the way that it does, and how we should model such variation. The final part of the book is a concluding chapter which tries to bring together some of the themes in the rest of the book.

In what follows, I assume minimal knowledge of formal aspects of linguistic description, discussing particular linguistic features as they emerge. Specific linguistic terms are defined on first use. An appendix has been provided which gives some guidance on phonetic transcription conventions.

All of the chapters conclude with some questions for discussion. Some of these questions are designed for more general discussion; others are designed to check your understanding of some of the concepts introduced in the chapter. But more generally I hope that this book encourages you to think of your own questions about English sociolinguistics, and how you might think of a project which could answer those questions.

\section{Further reading}

Each chapter of this book concludes with some reading on the specific topics introduced therein. Here I make some suggestions for general reading on sociolinguistics which complement this book. These texts 
include data from languages other than English, and are also typically about sociolinguistic theory and practice more generally.

An excellent introduction to many aspects of sociolinguistics is Meyerhoff (2006). Other very comprehensive introductions include Holmes (2001), Mesthrie et al. (2009) and Wardhaugh (2010); Chambers (2003) presents a particularly clear account of modern sociolinguistic theory. For handbooks, which present summaries of the main research grouped around particular topics, Chambers et al. (2002) is the standard for language variation and change, while Coulmas (1998) explores sociolinguistics more generally. In terms of a general theory of cognition, language and society, the textbook which comes closest to this one is Hudson (1996), though that book is not concerned with English exclusively. For introductions to sociolinguistic methodology, including the quantitative analysis of variable data, see Milroy and Gordon (2003) and (as mentioned above), Tagliamonte (2006). A comprehensive explanation of sociolinguistic terms is provided by Trudgill (2003) and Swann et al. (2004). 
